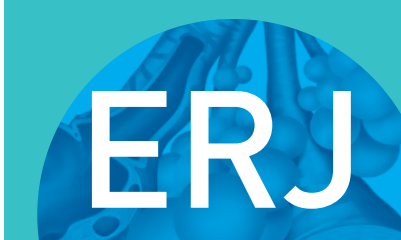

open research

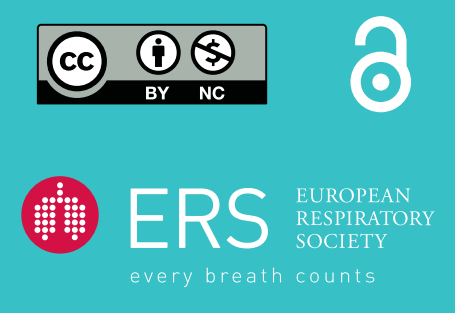

\title{
Are the "critical" inspiratory constraints actually decisive to limit exercise tolerance in COPD?
}

\section{To the Editor:}

Exercise intolerance is characteristically multi-factorial in patients with chronic obstructive pulmonary disease (COPD) [1]. At least in symptomatic patients with moderate-to-severe airflow limitation, higher operating lung volumes assume a relevant role in decreasing patients' tolerance to sustain "prolonged" exercise. As a consequence of the dynamic increase in the end-expiratory lung volume, tidal volume (VT) occurs close to total lung capacity (TLC), thereby reducing the room for further lung-chest wall expansion. The combination of low dynamic lung compliance and a severely reduced inspiratory reserve volume causes a mismatch between a growing respiratory neural drive and the resulting lung-chest wall displacement [2]. It has been postulated that such critical inspiratory constraints (CIC) lead to a plateau in VT, and a concomitant increase in dyspnoea as a function of ventilation $\left(V_{E}^{\prime}\right)$ [3]. Accordingly, patients change their perception of the uncomfortable respiratory sensations from "laboured breathing" to "insufficient inspiration", prompting early exercise termination [4].

The CIC concept, however, has so far been scrutinized in groups of patients performing a single bout of incremental exercise or in pre- versus post-intervention studies (as reviewed, for instance, in [5]). Thus, relevant between-subject discrepancies might have been obscured by mean data analysis. In other words, these studies do not allow unequivocal inferences on whether the CIC, and the exercise intensity associated with a change in dyspnoea intensity and quality, consistently occur at the same $V_{\mathrm{E}}^{\prime}$ in a given individual (research question (a)). Moreover, they do not permit a clear appreciation of whether this would be the case regardless of the rate of increase in $V_{\mathrm{E}}^{\prime}$, i.e. to which extent the CIC are not protocol dependent (research question (b)). Importantly, they did not address the value of the CIC in discriminating a "sustainable" from a "non-sustainable" exercise intensity domain (question (c)). We reasoned that, by answering these research questions, we could obtain a clearer picture of the actual validity of the CIC concept to explain dyspnoea and exercise intolerance in COPD.

In order to answer research questions (a) and (b), eight men with moderate-to-severe COPD (aged between 52 and 81 years, $\mathrm{FEV}_{1}=52.3 \pm 15.1 \%$ predicted, residual volume $=181.3 \pm 27.9 \%$ predicted, transfer factor $=50.4 \pm 14.2 \%$ predicted) performed, on different days, two ramp-incremental CPETs on a cycle ergometer with serial measurements of inspiratory capacity (IC) and dyspnoea intensity (0-10 Borg category ratio scale) and quality every minute ("which phrase better reflects what you are feeling now: My breathing requires more effort or I cannot get enough air in") [6]. Patients were instructed to maintain their current treatment for COPD, i.e. bronchodilators and, in six patients, inhaled corticosteroids. An upward shift in dyspnoea- $V_{E}^{\prime}$ was defined as a sudden increase in dyspnoea ( $\geqslant 2$ Borg units) which remained on the rise up to exercise termination. Physiological data were averaged as the arithmetic mean of $60 \mathrm{~s}$. We estimated the maximum breathing capacity $\left(\mathrm{MBC}_{\text {est }}, \mathrm{L} \cdot \mathrm{min}^{-1}\right)$ as $\mathrm{FEV}_{1} \times 40$; thus, breathing reserve (\%) was calculated as:

$$
\text { Breathing reserve }=\left(100-\frac{\text { peak } V_{E}^{\prime}}{\mathrm{MBC}_{\mathrm{est}}}\right) \times 100
$$

@ERSpublications

The concept of critical inspiratory constraints is key to the modern understanding of exercise pathophysiology in patients with moderate-to-severe COPD https://bit.ly/2A6bCxD

Cite this article as: Marillier M, Bernard A-C, Gass R, et al. Are the "critical" inspiratory constraints actually decisive to limit exercise tolerance in COPD? ERJ Open Res 2020; 6: 00178-2020 [https://doi.org/10.1183/23120541.00178-2020]. 
On day 1 , the rate of work rate increase was individually chosen according to current practice (i.e. an increment rate based on subjects' fitness and reported dyspnoea on daily life aiming at a ramp duration between 8 and $12 \mathrm{~min}$ ) [7], whereas on day 2, the rate of work rate increment was halved $\left(\mathrm{CPET}_{\mathrm{inc}}\right.$ and $\mathrm{CPET}_{\text {inc/2, }}$, respectively). On each day, the CIC were established when VT plateaued as a function of increasing $V_{\mathrm{E}}^{\prime}\left(V_{\mathrm{E}_{\mathrm{CIC}}}^{\prime}\right)$. We defined the $\mathrm{VT}$ plateau as a variation $<0.15 \mathrm{~L}$ and/or $<5 \%$ predicted $\mathrm{VT}$ [8] (whichever was greater), provided the VT/IC ratio $\geqslant 0.8$ and/or the end-inspiratory lung volume/TLC ratio $\geqslant 0.9$ [9]. In order to answer research question (c), the patients were invited for two additional visits (day 3 and day 4). In these visits, they were asked to exercise, on a random order, to symptom limitation or $20 \mathrm{~min}$ at constant work rates (estimated from the $V^{\prime}{ }^{-}$-work rate relationship during $\mathrm{CPET}_{\text {inc }}$ ) able to elicit $90 \pm 5 \%$ of $V^{\prime} \mathrm{E}_{\mathrm{CIC}}$ or $110 \pm 5 \% V^{\prime} \mathrm{E}_{\mathrm{CIC}}$.

Exercise duration was within the desired time range in response to $\mathrm{CPET}_{\mathrm{inc}}$ in all patients (ramp duration between 7.6 and $11.7 \mathrm{~min}$ ). As expected, test duration increased in response to $\mathrm{CPET}_{\mathrm{inc} / 2}$ (figure 1a for a representative patient (\# 3)). We were able to identify the CIC in each patient (figure $1 \mathrm{~b}$ for the representative patient). The CIC followed IC decreases from rest of $-0.21 \pm 0.30 \mathrm{~L}$, being associated with $\mathrm{VT} / \mathrm{IC}$ of $0.86 \pm 0.06 . V_{\mathrm{E}_{\mathrm{CIC}}}$ was similar in $\mathrm{CPET}_{\mathrm{inc}}$ minus $\mathrm{CPET}_{\mathrm{inc} / 2}(1.8,-2.0,2.2,-1.8,1.6,-3.4,3.2$ and $2.8 \mathrm{~L} \cdot \mathrm{min}^{-1}$ at average breathing reserves of $32.3 \%, 26.1 \%, 24.6 \%, 34.3 \%, 30.2 \%, 21.4 \%, 26.2 \%$ and $28.1 \%$ for patients $\# 1$ to $\# 8$, respectively). $V_{\mathrm{E}_{\mathrm{CIC}}}$ did not differ from $V_{\mathrm{E}}^{\prime}$ associated with an upward inflection in dyspnoea in both tests (mean difference $\pm \mathrm{SD}=2.4 \pm 2.1$ and $1.9 \pm 2.6 \mathrm{~L} \cdot \mathrm{min}^{-1}$ for $\mathrm{CPET}_{\text {inc }}$ and $\mathrm{CPET}_{\mathrm{inc} / 2}$, respectively; $\mathrm{p}>0.05$ for both comparisons (paired $t$-test)). The corresponding values for the differences in $V^{\prime} \mathrm{E}_{\mathrm{CIC}}$ and the $V_{\mathrm{E}}^{\prime}$ associated with a change in sensory quality of dyspnoea to "I cannot get enough air in" (figure $1 \mathrm{c}$ for the representative patient) were: $3.4 \pm 2.7$ and $2.2 \pm 2.0 \mathrm{~L} \cdot \mathrm{min}^{-1}$, respectively; $\mathrm{p}>0.05$. The correlation coefficients between $V_{\mathrm{E}}^{\prime}$ corresponding to the VT plateau versus the dyspnoea $V_{\mathrm{E}}^{\prime}$ inflection and the $V_{E}^{\prime}$ associated with a change in sensory quality of dyspnoea were: $r=0.82$ and $r=0.88\left(\mathrm{CPET}_{\text {inc }}\right)$ and $\mathrm{r}=0.76$ and $\mathrm{r}=0.80\left(\mathrm{CPET}_{\mathrm{inc} / 2}\right)$, respectively $(\mathrm{p}<0.01$ for all $)$.
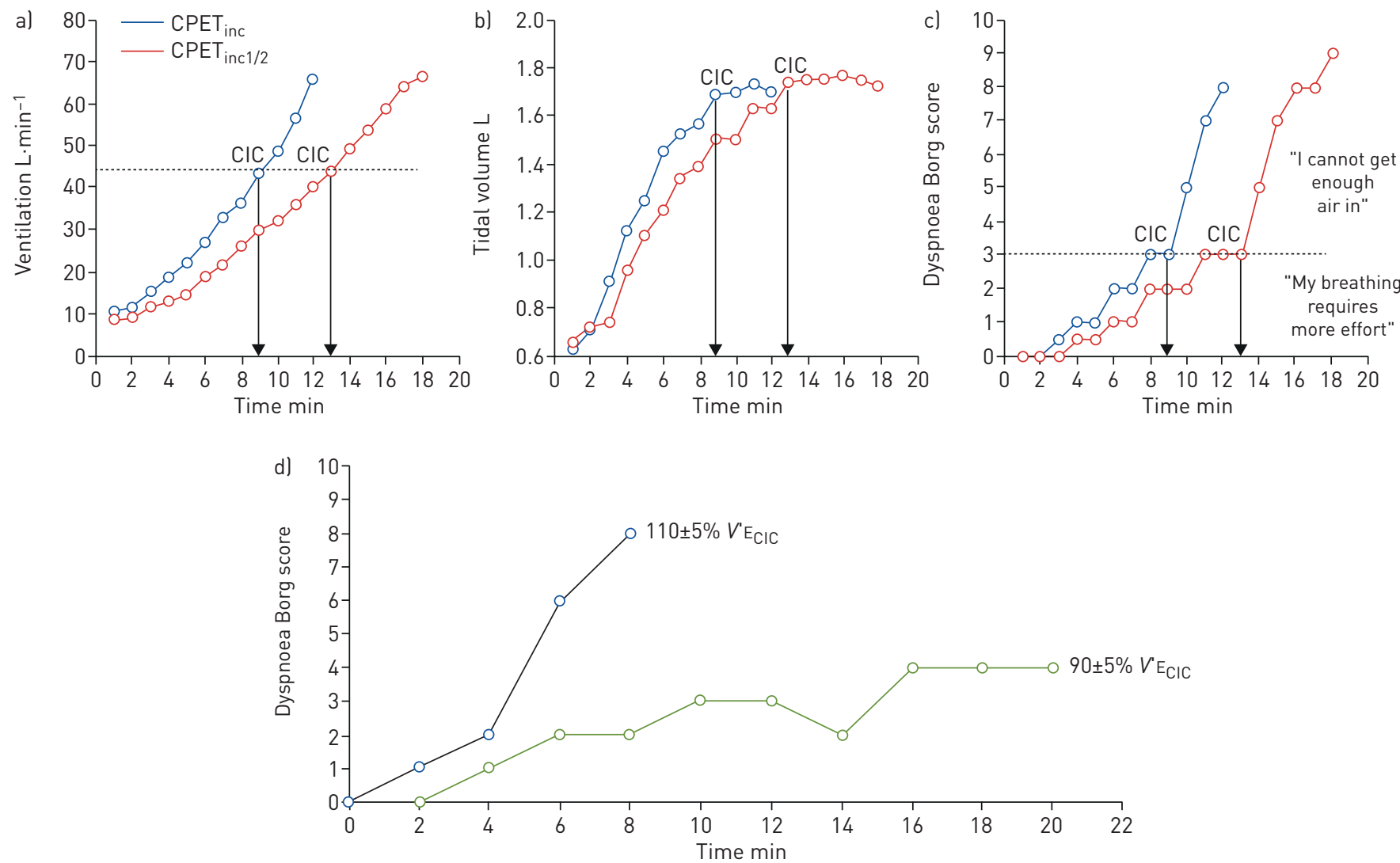

FIGURE 1 Physiological and sensory responses to exercise in a patient with moderate COPD (subject 3). a-c) The responses to two ramp-incremental cardiopulmonary exercise tests (CPET): a test in which the work rate increment was selected aiming at a ramp duration

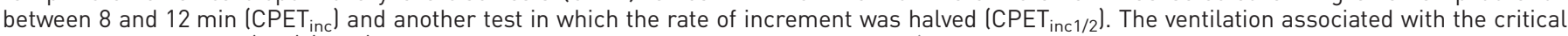
inspiratory constraints $(\mathrm{CIC})\left(V^{\prime} E_{C I C}\right)$ was determined by the joint analysis of a and b. d) The same patient performing two constant work rate tests: a test below $V^{\prime} E_{C I C}$ and another test above the $V^{\prime}{ }_{E_{C I C}}$. In the latter tests, the patient was told to sustain exercise to the limit of tolerance or a maximum of $20 \mathrm{~min}$. See the text for elaboration. 
All patients sustained $90 \pm 5 \% V^{\prime} \mathrm{E}_{\mathrm{CIC}}$ (work rate of $42 \pm 20 \mathrm{~W}$ or $74.2 \pm 18.6 \%$ peak work rate) for the desired timeframe reporting stable dyspnoea (typically 3-4/10); in contrast, dyspnoea progressively increased (peak values ranging from 5 to $9 / 10$ ) when the patients exercised at $110 \pm 5 \% V_{\mathrm{E}_{\mathrm{CIC}}}^{\prime}$ (work rate of $54 \pm 17 \mathrm{~W}$ or $85.4 \pm 15.3 \%$ peak work rate). As a consequence, no patient was able to sustain the latter test for $20 \mathrm{~min}$ $(6.4,7.0,7.9,6.8,8.6,11.3,9.4$ and $12.9 \mathrm{~min}$, respectively) (figure $1 \mathrm{~d}$ for the representative patient). Overall, a significantly higher total work load $(\mathrm{kJ}=(\mathrm{W} \times \mathrm{s}) / 1000)$ was performed during the tests at $90 \pm 5 \%$ $V^{\prime} \mathrm{E}_{\mathrm{CIC}}(51.3 \pm 22.6 \mathrm{~kJ})$ compared to the tests at $110 \pm 5 \% V_{\mathrm{E}_{\mathrm{CIC}}}^{\prime}(32.6 \pm 14.4 \mathrm{~kJ})(\mathrm{p}<0.05)$.

Our results give strong experimental support to the notion that the CIC have important pathophysiological implications for patients with COPD [10]. We challenged its physiological-sensory foundations (research question (a)), robustness (research question (b)) and consequences to exercise tolerance (research question (c)). In each of these instances, we failed to negate the validity (and precision) of the concept. In fact, we have recently demonstrated that either in subjects under investigation for undetermined dyspnoea [11] or patients with COPD [9], the CIC were instrumental to explain the presence and severity of exertional dyspnoea. We were rather surprised, however, by the fact that the CIC were independent of the $V_{\mathrm{E}}^{\prime}$ "history" (figure 1a). For instance, it could have been anticipated that a slow rate of increase in $V_{\mathrm{E}}^{\prime}$ during $\mathrm{CPET}_{\text {inc1/2 }}$ would not only delay the CIC but also lead it to occur at a higher $V_{\mathrm{E}}^{\prime}$. This was not the case because the CIC occurred at similar breathing frequencies and VT, likely reflecting an equally critical expiratory time to fully expire a given inspired volume [12]. It is possible, however, that faster ramps (compared to $\mathrm{CPET}_{\mathrm{inc}}$ ) would have produced different $V_{\mathrm{E}_{\mathrm{CIC}}}^{\prime}$ in some patients.

Other results deserve some specific comments. In more severe patients, we [13] and others [14] have previously described that patients with COPD consistently terminate high-intensity exercise when $V_{\mathrm{E}}^{\prime}$ approached the MBC. In contrast, we herein found that $V^{\prime}{ }_{\mathrm{E}_{\mathrm{CIC}}}$ coexisted with substantial breathing reserves. Even considering the differences in patients' severity, it is noteworthy that we found in other studies that the CIC may indeed happen at exercise intensities well below the (estimated) MBC [9]. This is particularly true when the $\mathrm{MBC}$ is a high value and the patients do not present with severe ventilatory inefficiency [15]. In other words, a combination of a high $\mathrm{MBC}$ with relatively low submaximal $V^{\prime}{ }_{\mathrm{E}}-\mathrm{CO}_{2}$ output may give more time for the CIC to emerge during a ramp-incremental CPET. This line of reasoning seems to provide a good justification to avoid excessively steep ramps in these patients. From a practical perspective, it is also interesting to observe that a ventilatory level selected in an incremental test showed physiological relevance when applied to a constant load test (figure 1d). Thus, these differing test formats may have a higher degree of interchangeability than hitherto assumed.

Our study has some relevant limitations. Considering the complexities involved in performing several exercise tests on different days, the sample size was necessarily small. Larger studies involving men and women might clarify whether sex bears an influence on the $V_{\mathrm{E}_{\mathrm{CIC}}}$-dyspnoea relationship. We recognise the descriptive nature of our study; for instance, we did not test the stability of the $V^{\prime} \mathrm{E}_{\mathrm{CIC}}$-dyspnoea relationship in response to interventions potentially able to improve $V_{\mathrm{E}_{\mathrm{CIC}}^{\prime}}$, e.g. inhaled bronchodilators. Due to the inherent limitation of discrete dyspnoea readings at selected time points (and the constraints of minute-by-minute data averaging), we have relatively few data points for analysis on each test. Thus, larger discrepancies between $V_{E_{\mathrm{CIC}}}^{\prime}$ and dyspnoea may have emerged if a higher number of data points were available for comparison. In fact, the "best" approach for data averaging to obtain reliable and reproducible readings of the VT plateau remains unknown. Additional studies are warranted to test whether the work rate associated with $90 \pm 5 \% V_{\mathrm{E}_{\mathrm{CIC}}}^{\prime}$ can be validly used to estimate the highest tolerable intensity to be used during rehabilitative exercise training in these patients. In fact, more work was performed during this test compared to the test at $110 \pm 5 \% V^{\prime} \mathrm{E}_{\mathrm{CIC}}$ since its longer duration more than counterbalanced a lower exercise intensity.

In conclusion, we herein demonstrated that the concept of CIC is relevant to the current understanding of exercise pathophysiology in patients with moderate-to-severe COPD. By making these patients exercise at ventilatory levels below $V^{\prime} \mathrm{E}_{\mathrm{CIC}}$, the clinician can markedly lessen their activity-related dyspnoea with consequent benefits to exercise tolerance.

Mathieu Marillier ${ }^{1,2}$, Anne-Catherine Bernard ${ }^{1,2}$, Ricardo Gass ${ }^{3}$, Danilo C. Berton $\odot^{3}$, Samuel Verges ${ }^{2}$, Denis E. O’Donnell $\odot^{1}$ and J. Alberto Neder $\odot^{1}$

${ }^{1}$ Laboratory of Clinical Exercise Physiology and Respiratory Investigation Unit, Queen's University and Kingston General Hospital, Kingston, ON, Canada. ${ }^{2}$ HP2 Laboratory, INSERM U1042, Grenoble Alpes University, Grenoble, France. ${ }^{3}$ Division of Respirology, Federal University of Rio Grande do Sul, Porto Alegre, RS, Brazil.

Correspondence: J. Alberto Neder, 102 Stuart Street, Kingston, ON, Canada K7L 2V6. E-mail: alberto. neder@queensu.ca 
Received: 8 April 2020 | Accepted after revision: 21 June 2020

Conflict of interest: None declared.

\section{References}

1 O'Donnell DE, Laveneziana $\mathrm{P}$, Webb $\mathrm{K}$, et al. Chronic obstructive pulmonary disease: clinical integrative physiology. Clin Chest Med 2014; 35: 51-69.

2 Faisal A, Alghamdi BJ, Ciavaglia CE, et al. Common mechanisms of dyspnea in chronic interstitial and obstructive lung disorders. Am J Respir Crit Care Med 2016; 193: 299-309.

3 Casaburi R, Rennard SI. Exercise limitation in chronic obstructive pulmonary disease. The O'Donnell threshold. Am J Respir Crit Care Med 2015; 191: 873-875.

4 O'Donnell DE, Laveneziana P. Dyspnea and activity limitation in COPD: mechanical factors. COPD 2007; 4: 225-236.

5 O'Donnell DE, Elbehairy AF, Faisal A, et al. Exertional dyspnoea in COPD: the clinical utility of cardiopulmonary exercise testing. Eur Respir Rev 2016; 25: 333-347.

6 Mahler DA, O'Donnell DE. Recent advances in dyspnea. Chest 2015; 147: 232-241.

7 American Thoracic Society, American College of Chest Physicians. ATS/ACCP statement on cardiopulmonary exercise testing. Am J Respir Crit Care Med 2003; 167: 211-277.

8 Neder JA, Dal Corso S, Malaguti C, et al. The pattern and timing of breathing during incremental exercise: a normative study. Eur Respir J 2003; 21: 530-538.

9 Neder JA, Berton DC, Marillier M, et al. Inspiratory constraints and ventilatory inefficiency are superior to breathing reserve in the assessment of exertional dyspnea in COPD. COPD 2019; 16: 174-181.

10 Laveneziana P, Webb KA, Ora J, et al. Evolution of dyspnea during exercise in chronic obstructive pulmonary disease: impact of critical volume constraints. Am J Respir Crit Care Med 2011; 184: 1367-1373.

11 Neder JA, Berton DC, Marillier M, et al. The role of evaluating inspiratory constraints and ventilatory inefficiency in the investigation of dyspnea of unclear etiology. Respir Med 2019; 158: 6-13.

12 O'Donnell DE, Elbehairy AF, Faisal A, et al. Canadian Respiratory Research Network (CRRN). Sensory-mechanical effects of a dual bronchodilator and its anticholinergic component in COPD. Respir Physiol Neurobiol 2018; 247: 116-125.

13 Neder JA, Jones PW, Nery LE, et al. Determinants of the exercise endurance capacity in patients with chronic obstructive pulmonary disease. The power-duration relationship. Am J Respir Crit Care Med 2000; 162: 497-504.

14 van der Vaart H, Murgatroyd SR, Rossiter HB, et al. Selecting constant work rates for endurance testing in COPD the role of the power-duration relationship. COPD 2014; 11: 267-276.

15 Neder JA, Berton DC, Arbex FF, et al. Physiological and clinical relevance of exercise ventilatory efficiency in COPD. Eur Respir J 2017; 49: 1602036. 